and carbon dioxide, as well as for vapours like benzene, carbon disulphide, chloroform, carbon totrachloride, etc., throughout the range of temperature where viscosity measurements are available.

The accompanying curve represents $\eta / \eta n$ plotted against $T / T_{B}$ as given by equation (3). It will be noticed that the observed points for air, argon, hydrogen, carbon dioxide and benzene all fall on this 'universal curve'. The fit is equally good in the case of other gases and vapours. The formula holds for ordinary range of pressures. Since the boiling point depends on pressure, equation (2) indicates the dependence of the viscosity of a gas on pressure. It may be noted, however, that for pressure changes which are not large, variation in the boiling point and the resulting variation of viscosity would be scarcely observable. A change in the indicated direction is, however, to be found in the experimental results of Kundt and Warburg when the pressure change is not very large.

The detailed account of this work is being published elsewhere.

Physics Department,

University of Delhi, Delhi.

May 10.

' Farshad, R., Indian J. Phys., 15, 323 (1941).

\section{Structure of Geranylamine Hydrochloride}

THE ambiguity in the interpretation of fibre diagrams makes it doubtful whether satisfactory solutions for the crystal structures of rubber and the gutta-percha isomers will be possible until a more detailed knowledge of the stereochemistry of the polyisoprene system is available. Accordingly a complete crystal structure analysis has been made on the simple di-isoprene derivative, geranylamine hydrochloride,

$\mathrm{CH}_{3} \cdot \mathrm{C} \cdot\left(\mathrm{CH}_{3}\right): \mathrm{CH} \cdot \mathrm{CH}_{2} \cdot \mathrm{CH}_{2} \cdot \mathrm{C} \cdot\left(\mathrm{CH}_{3}\right): \mathrm{CH}_{2} \mathrm{CH}_{2} \cdot \mathrm{NH}_{2} \cdot \mathrm{HCl}$.

From the experimental data of 1,060 observed refloxion intensities, it has been possible by extensive trial and error calculations followed by threedimensional Fourier syntheses to establish the parameters for each atom (excluding hydrogen) to an accuracy of about $\pm 0.03 \mathrm{~A}$. The space group is $P 2_{1 / c}$, and a diagram of the two glide-related molecules projected on to half the basal plane of the monoclinic cell is shown in the accompanying illustration. The interatomic distances are as follows :

$$
\begin{array}{llllll}
\mathrm{Cl}-\mathrm{N} & 3.23 \mathrm{~A} . & \mathrm{C}_{2}-\mathrm{C}_{8} & 1.31 \mathrm{~A} & \mathrm{C}_{8}-\mathrm{C}_{2} & 1.52 \mathrm{~A} \\
\mathrm{~N}-\mathrm{C}_{1} & 1.49 & \mathrm{C}_{3}-\mathrm{C}_{4} & 1.53 & \mathrm{C}_{7}-\mathrm{C}_{8} & 1.31 \\
\mathrm{C}_{2}-\mathrm{C}_{8} & 1.54 & \mathrm{C}_{8}-\mathrm{C}_{8} & 1.51 & \mathrm{C}_{8}-\mathrm{C}_{8} & 1.53 \\
& & \mathrm{C}_{8}-\mathrm{C}_{4} & 1.43 & \mathrm{C}_{3}-\mathrm{C}_{10} & 1.54
\end{array}
$$

In both isoprene units, which are identical, the disposition of valencies about the ethylenic double bond is strictly planar and the angles are normal to within $\pm 5^{\circ}$.

The most significant feature of the structure is the shortening of the $\mathrm{C}_{5}-\mathrm{C}_{6}$ bond, accompanied by a planar configuration of carbon atoms $3,5,6$ and 7 . This implies a hybrid bond comparable, for example, to the formally single bond in butadiene. The double bonds cannot be considered as completely insulated and some degree of triene conjugation must be envisaged, $-\mathrm{C}=\mathrm{C}-\mathrm{C} \cdots \mathrm{C}-\mathrm{C}=\mathrm{C}-$. Since it is not apparent how the saturated quaternary ammonium pole can be solely responsible for this molecular modi-

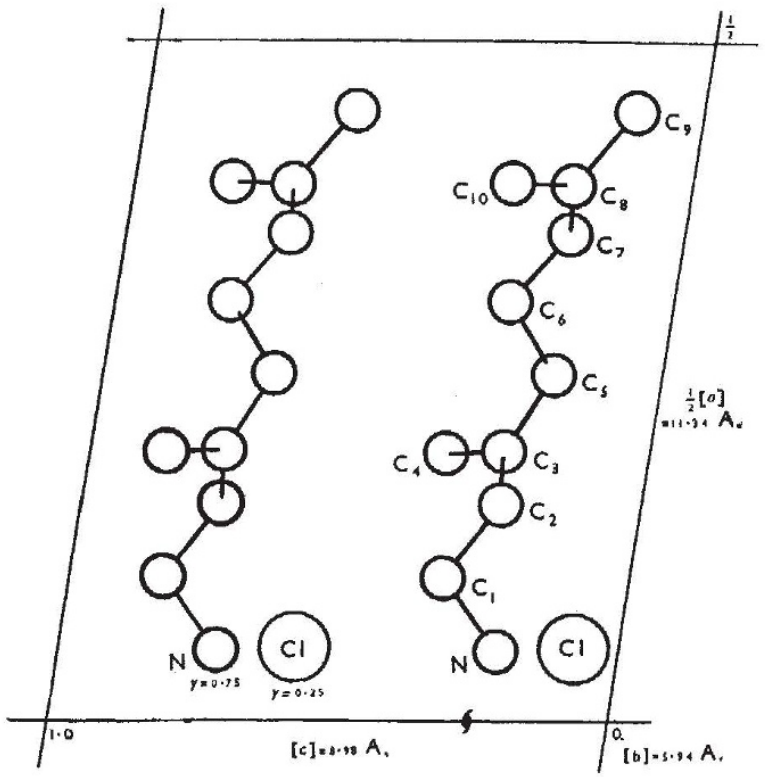

fication by creating appropriate canonical states, the high electrostatic charge of the $\mathrm{N}+$ must be considered as merely enhancing an effect inherent in the hydrocarbon system. After inductive transmission to the nearer double bond, electron attraction farther along the chain will only be appreciable if it can be relayed by a tautomerio (mesomeric) displacement. Precisely such a mechanism is provided by invoking and developing the incipient conjugation previously suggested $^{1}$ as a normal feature of 1 : 5 diene systems by virtue of hyperconjugation involving the $\alpha$ methylenic $\mathrm{C}-\mathrm{H}$ bonds.

The details of the complete $\mathrm{X}$-ray analysis will be published elsewhere, together with a discussion of its bearing upon the problems of the natural polyisoprene structures.

British Rubber Producers' Research

L. Bateman.

G. A. JEEFREY,

Association,

48 Tewin Road,

Welwyn Garden City.

${ }^{3}$ Bateman, L., Trans. Faraday Soc., 38, 367 (1942).

\section{A New Technique for the Ultimate Microanalysis of Organic Compounds}

UNDER this title, Ronald Belcher and Cyril E. Spooner ${ }^{1}$ have described an apparatus for the combustion of organic compounds, consisting of a combustion tube which is not filled with any contact material. The authors refer to their previous publication of a similar macro-method ${ }^{2}$, and state that they "originated this unpacked tube technique for the ultimate analysis of Coal", and further say that "so far as we are aware this was the first use of an unpacked tube for this purpose, and we have now adapted it to the micro-scale"

In view of these claims may I be allowed to state that neither combustion analysis without contact material nor its adaptation to the micro-scale are new. In fact, this kind of technique has been re. peatedly described by a number of authors from 1864 up to the present time, namely, by C. N. Warren ${ }^{3}$, 